引用格式: 丁琳琳, 吴群. 环境约束下中国工业用地投人对经济增长的影响一一基于 “绿色索洛模型” 的分析[J]. 资源科学, 2017,39(4) : 620-628. [Ding L L, Wu Q. The impact of industrial land input on economic growth under environmental restraints in China: analysis based on the Green Solow Model[J]. Resources Science, 2017,39(4) : 620-628.] DOI: 10.18402/resci.2017.04.04

\title{
环境约束下中国工业用地投入对经济增长的影响 基于“绿色索洛模型”的分析
}

\author{
丁琳琳 $^{1,2}$,吴 群 ${ }^{1,2}$
}

(1. 南京农业大学公共管理学院, 南京 210095; 2. 南京农业大学土地价格与市场研究室, 南京 210095)

\begin{abstract}
摘 要:工业生产促进经济增长的过程内含“环境代价”, 一定程度上造成了经济损失。本文在理论上构建了 包含土地和环境要素在内的“绿色索洛模型”, 考察工业用地投入和环境污染对经济增长的影响与约束, 以消除工 业经济增长中的环境代价。并利用中国 2000-2010年省际面板数据进行实证检验。研究结果表明: (1)环境约束下, 索洛模型仍存在平衡增长路径; (2)土地要素对经济增长呈正向作用, 但地区间存在差异, 其中中部地区影响最大, 东部地区次之, 西部地区最小; 3 环境要素对经济增长的影响取决于正/负效应共同的作用结果, 总体来看, 除工业 固体废弃物外, 工业废水、工业 $\mathrm{SO}_{2}$ 、工业 $\mathrm{NO}_{\mathrm{x}}$ 、工业烟(粉) 尘等的排放对经济增长均呈明显抑制作用, 且工业废气 对经济增长的抑制作用较工业废水更强。在未来经济发展中, 应摒弃传统的“低成本”工业化模式,积极探索建立 绿色国民经济核算体系; 同时加快用地企业科技创新, 尤其是环境保护和污染治理方面的科技创新,减少工业用地 投产过程中的环境外部性
\end{abstract}

关键词: 工业用地投入; 环境污染; 经济增长;绿色索洛模型; 中国

DOI: $10.18402 /$ resci.2017.04.04

\section{1 引言}

1996年中国开始加快工业化进程,之后城市经 济迅速发展。中国工业经济也一直保持较高增长 速度, 2014 年中国工业产值高达 227991 亿元, 占 GDP 的比重为 $35.82 \%$ 。但工业生产的本质是人类 对物质资源形态的改变,其在消耗自然资源的同时 还会产生环境污染 ${ }^{[1]}$ 。近年来, 中国的能源净进口、 环境污染、生态恶化等问题不断加剧。据统计, 2011 年中国单位美元 GDP 的 $\mathrm{CO}_{2}$ 排放量是美国的 3.5 倍, 单位能源消耗生产的 GDP也只占到发达国 家的 50\%左右。全国因环境污染造成的经济损失 在 2004 年已超过 5000 亿元, 为治理环境污染, 中国 每年实际的污染治理项目投资总额逐年增加, 20012014 年间,已从 175 亿元增加到了 998 亿元, 成为政 府很大的财政负担。由此可见，以环境污染和能源
消耗为代价的经济发展模式是不可持续的。

目前的研究主要集中在工业用地效率的测度 方面 ${ }^{[2,3]}$, 也有学者通过构建广义的生产函数模型来 解释工业用地的经济增长效应 ${ }^{[4,5]}$ 。但如果不考虑 环境因素, 容易过高估计工业用地投人对经济增长 的影响。在资源环境日益成为经济增长硬约束的 背景下, 部分学者开始尝试将环境要素纳人到 DEA 测算模型中去 ${ }^{[6]}$ 。

要获得消费品,一般会伴随污染。通常来讲, 将非期望产出纳人到模型中有两种不同的思路:第 一种是将环境污染等非期望产出作为生产要素投 人处理;二是将工业“三废”等非期望产出作为经济 活动的副产品引人。参考已有研究 ${ }^{[7,8]}$,本文将污染 物作为环境投人要素引人生产函数。污染排放作 为投人会通过两种方式作用于经济增长:一种是利

收稿日期: 2016-08-10; 修订日期: 2017-01-05

基金项目: 高等学校博士学科点专项科研基金资助项目(20130097110039);国家自然科学基金(重点)资助项目(71233004)。

作者简介: 丁琳琳,女,河南漯河人,博士生,主要研究方向为土地经济与管理。E-mail:724632699@qq.com

通讯作者: 吴群,E-mail : wuqun@njau.edu.cn 
用自然环境吸纳和沉积废弃物的功能发挥社会资 本的作用,某些经济活动单位通过对自然环境的消 耗可以在给定其他投人的前提下增加它的产出水 平, 此时, 排放物对经济增长的影响为正; 但持续的 环境资本消耗会导致总的社会资本的下降,进而降 低自然环境的质量,这时排放物对经济增长的影响 则是负的。即在没有环境管制的情况下,污染排放 物对经济增长的作用取决于正/负效应的总和, 总体 来讲,当正效应大于负效应时,污染物对经济增长 具有促进作用; 反之, 污染物则阻碍经济增长。由 此,本文拟在考察工业用地投人对经济发展的作用 路径的分析中, 纳人环境要素的影响,进一步研究 土地要素对工业经济增长的贡献。在此基础上,构 建内含环境要素的“绿色索洛模型”,并利用省际面 板数据进行实证检验与分析。最后归纳总结并提 出政策建议。

\section{2 工业用地投入对经济发展的作用路 径分析}

近年来, 中国的环境污染问题逐步加剧,如图 1 所示, 以工业 $\mathrm{SO}_{2}$ 和 $\mathrm{NO}_{\mathrm{x}}$ 的排放为例, 环境污染物的 排放量居高不下,GDP 增长率也在经历 2007 年的 顶峰之后开始不断下降。可以说,工业化在给经济 发展做出贡献的同时,其带来的环境污染和资源损 耗也给经济造成了巨大损失。按照可持续发展理 论, 当代人的发展不能建立在剥夺后代人发展潜力
的基础上。但工业化生产的负外部性不仅损害了 当代人的利益，同时其造成的经济损失还会作为一 种成本遗留在未来经济发展中,造成代际矛盾。一 定程度上可以将工业经济增长视为当代人土地利 用行为的一种回报,而环境污染等造成的经济损失 则是当代人透支了后代人的利益。如果当代人享 用经济发展成果而让后代人承担“环境代价”, 不仅 对后代人不公平,也会严重影响中国经济的可持续 发展。

探索工业用地投人对经济增长的影响,首先要 了解工业生产对地方经济发展的作用路径。而实 际上,工业用地投产后不仅能够促进地方经济快速 增长, 同时工业生产的负外部性一定程度上还会阻 碍经济的发展。工业用地对地区经济发展的快速 推动作用主要表现在以下三个方面:

(1)分税制改革后地方政府面临“财权上移、事 权下放”的困境,急需拓展新的财政收人来源。为 了招商引资,地方政府经常以成本价甚至“零地价” 的方式出让工业用地,但工业企业投产后,一方面 地方政府能够获得数额可观的增值税和企业所得 税等税收收人,另一方面工业发展还具有“溢出效 应”, 即工业企业发展会推动本地服务业部门增长 并带来相关营业税和商住用地土地出让金等收人 ${ }^{[11-13]}$ 。 这些收人满足了地方政府的财政预算需求,进而通 过增加基础设施投资等方式来进一步促进地区经

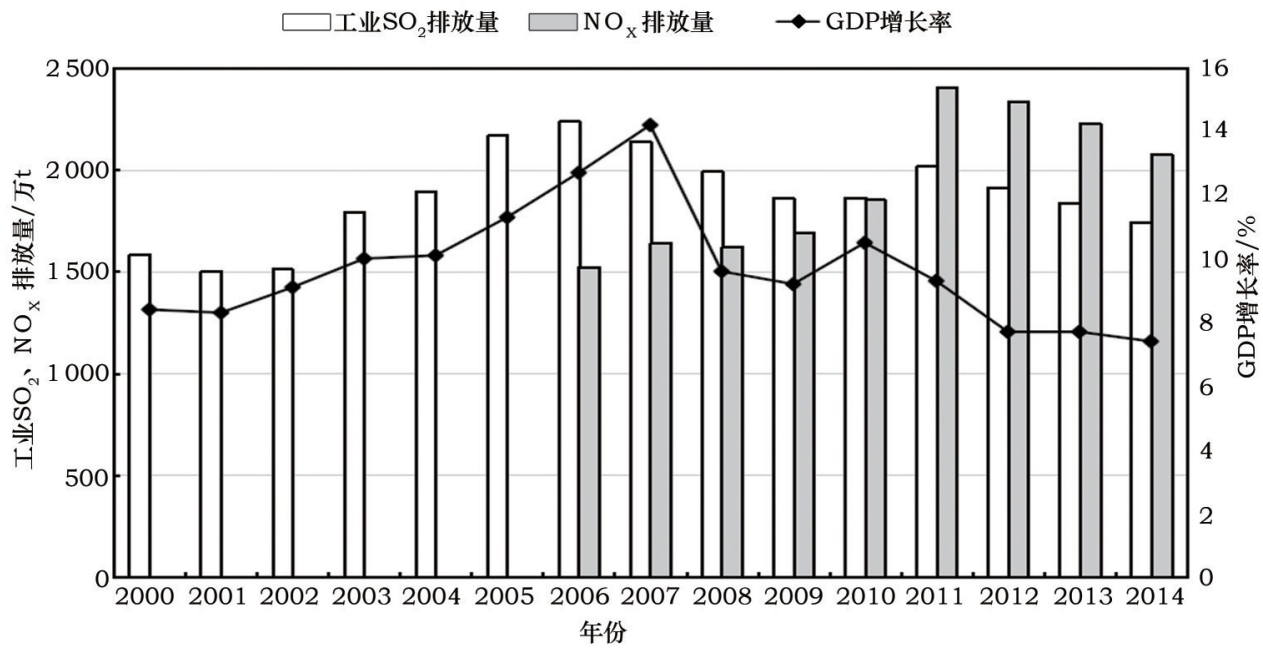

图 1 2000-2014 年中国 GDP 增长率与主要空气污染物排放情况

Figure 1 China's GDP growth rate and major air pollutant emissions from 2000 to 2014

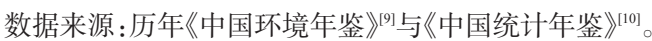


济增长。

(2)工业生产吸引了大量外资进人, 不仅能够 推动地区外向型经济的发展, 还能够加快对传统工 业产业的改造和对新兴支柱产业的扶持, 从而全面 拉动区域经济的快速增长。

(3) 以廉价的工业用地为载体的工业园区是目 前区域经济发展的重要政策工具, 工业企业向园区 的聚集,会导致集聚经济的产生 ${ }^{[14]}$,进而以产业合力 的形式促进地区经济的发展。

但工业用地在投产促进区域经济发展的同时 还会对环境产生负外部性。工业生产过程会产生 废弃物 (包括固体、液体和气体废弃物), 对自然环 境产生影响, 从而造成环境的改变,而环境改变则 会影响经济发展。环境变化对经济增长的作用主 要表现在两个方面:

(1)污染治理成本的存在会影响企业的产出水 平。当重大环境污染事故发生时,中央政府的强力 介人促使地方政府选择高水平的环境规制,这时企 业的产出水平会受到直接影响 ${ }^{[15]}$ 。此外,近几年国 务院要求在工业园区等重点领域,推行环境污染第 三方治理模式,变“谁污染谁治理”为“谁污染谁买 单”。企业在做出生产决策时一般会考虑污染治理 费用,从而间接影响产出水平。

(2)环境政策的实施会改变地区产业结构 ${ }^{[16-18]}$, 从而影响经济增长。工业“三废”的排放会对环境 造成极大污染,如果实行严格的环境保护政策,尽 管一定程度上能够敦促工业企业加大对废弃物的 处理力度、使用清洁能源或者改进生产技术, 但这 会增加企业的生产成本, 从而导致一些小企业停产 或迁出原生产地。无论是企业选择停产还是外移, 都会削弱地区经济发展实力。

\section{3 研究方法与数据来源}

1956 年麻省理工学院罗伯特·索洛教授关于经 济均衡增长路径的文章中,第一次引人了长期经济 增长模型, 并于 1987 年获得了诺贝尔奖。其基本思 路是, 保持劳动力和技术不变, 然后逐步放宽假设, 研究经济增长。然而, 索洛模型是不完备的, 按其 推论, 当资本存量增长时, 经济增长会放缓, 最终停 止。事实上过去 100 多年间,许多国家保持了正常 的增长量, 没有长期下降的趋势。尽管索洛模型的
假设条件过于理想,但模型的形式和基本思想为其 扩展提供了很大便利。目前, 学者们根据自身研究 问题的需要, 主要通过重新定义、增加新的因素来 扩展索洛模型的应用。

单从 GDP 增长额的数值中, 看不出这背后的环 境污染以及由此造成的经济损失。2004年, Brock 等提出了“绿色索洛模型”, 研究经济增长与环境质 量之间的关系,实质上是对 1956年提出的索洛模型 的深度拓展, 其贡献是将污染削减因素补充到索洛 模型的假定中 ${ }^{[19]}$ 。因此,本文借鉴“绿色索洛模型”, 将环境要素纳人生产函数,扣除由于环境约束带来 的经济成本,修正工业用地投人对工业经济增长的 贡献。

\section{1 研究方法}

在单一部门索洛模型中, 假定储蓄率 $(s)$ 和资 本 $(K)$ 的折旧率 $(\delta)$ 外生不变, $Y$ 表示产出,生产函数 规模报酬不变, 劳动 $(L)$ 和知识 $(A)$ 分别以不变速度 $n$ 和 $g$ 增长 ${ }^{[20]}$ 。则标准的索洛模型及关于资本、劳 动、知识的假设表示如下:

$$
\left\{\begin{array}{l}
Y=F(K, A L) \\
\dot{K}=s Y-\delta K \\
\dot{L}=n L \\
\dot{A}=g A
\end{array}\right.
$$

式中 $(A L)$ 为有效劳动, 变量上的点表示变量对时间 求导数,后文中其他变量类同。

Brock等拓展的绿色索洛模型假设中提出了削 减强度,即经济活动中用于污染削减的部分所占比 例, 其作为外生变量被引入模型 ${ }^{[2]}$ 。因此,模型的假 定条件为: 污染不存在结构效应, 同时忽略技术进 步和环境政策变化对污染削减的影响。为了研究 污染对产出的影响,首先要确定污染排放总量。假 定每单位经济活动产生的初始污染量为 $\omega$ (常数), 污染削减量取决于经济活动规模 $(F)$ 和消耗在污染 削减上的经济努力 $\left(F^{\tau}\right) ; \tau$ 为污染削减量。假定该 函数规模报酬不变。则污染排放量 $E$ 表示为:

$$
\begin{aligned}
E & =\text { 污染产生量 }- \text { 污染削减量 } \\
& =\omega F-\omega \tau\left(F, F^{\tau}\right)=\omega F\left(1-\tau\left(1, \frac{F^{\tau}}{F}\right)\right) \\
& =\omega F \rho(\theta)
\end{aligned}
$$

其中 $\rho(\theta)=1-\tau\left(1, F^{\tau} / F\right), \theta=F^{\tau} / F$ 
式中 $\theta$ 为削减强度, 假定其为不变常数, 则扣除环境 污染, 用于最终产品的消费和投资的经济活动为:

$$
Y=F(1-\theta)
$$

其次, 考虑环境的自净作用。假定污染存量 $(X)$ 的初始水平为 $0, E$ 为单位时间排污量,则污染 存量的动态方程为:

$$
\dot{X}=E-\partial X
$$

式中 $\partial$ 为污染的自然净化率, 且 $\partial>0$ 。

由以上分析可得到拓展的考虑环境污染的“绿 色索洛模型”形式如下：

$$
\begin{aligned}
& y=f(k)(1-\theta) \\
& \dot{k}=s f(k)(1-\theta)-(\delta+n+g) k \\
& e=f(k) \omega \rho(\theta) \\
& \dot{X}=E-\partial X
\end{aligned}
$$

式中 $k=K / A L, y=Y / A L, e=E / A L, f(k)=F(k, 1)$; $f(k)$ 为每单位有效劳动的平均资本量的函数。

在 “绿色索洛模型” 中, $s f(k)(1-\theta)$ 和 $(\delta+n+$ $g) k$ 分别表示实际投资和持平投资 (为保持 $K$ 在现 有水平所必须进行的投资）。由于 $f(0)=0$, 当 $k=0$ 时, 实际投资和持平投资相等。当 $k$ 趋近于 0 时, $f^{\prime}(k)$ (对函数求一阶导) 无限大, 随着 $k$ 不断变大, $f^{\prime}(k)=0$, 而曲线 $(\delta+n+g) k$ 的斜率是一定的, 因此, 在 $(0, k)$ 上某一点两条曲线相交。由于 $f^{\prime \prime}(k)<0$ (对函数求二阶导), 表明两条曲线只相交一次 (如 图 2)。我们用 $k^{*}$ 表示当实际投资与持平投资相等 时 $k$ 的值。如果 $k$ 最初小于 $k^{*}, k$ 为正, $k$ 将不断增 加直到到达 $k^{*}$; 如果 $k$ 大于 $k^{*}, k$ 为负, 则 $k$ 将不断 减小直到到达 $k^{*}$; 如果 $k$ 等于 $k^{*}, \dot{k}$ 为 0 。即不管 $k$ 从何处开始,它都向 $k^{*}$ 收玫。因此,同标准索洛模 型一样,绿色索洛模型下经济也收敛且仅收玫于惟 一的 $k^{*}$ 。

根据假定, $L$ 和 $A$ 分别以不变速度 $n$ 和 $g$ 增长, 由于 $k=K / A L$, 因此当 $k=k^{*}$ 时, 增长速度为 $(n+g)^{1)}$ 又由于生产函数规模报酬不变, 则产出 $Y$ 的增长速 度也为 $(n+g)$ 。因此, 将环境因素纳人生产函数后, 平衡增长路径上的增长率和标准索洛模型相同。

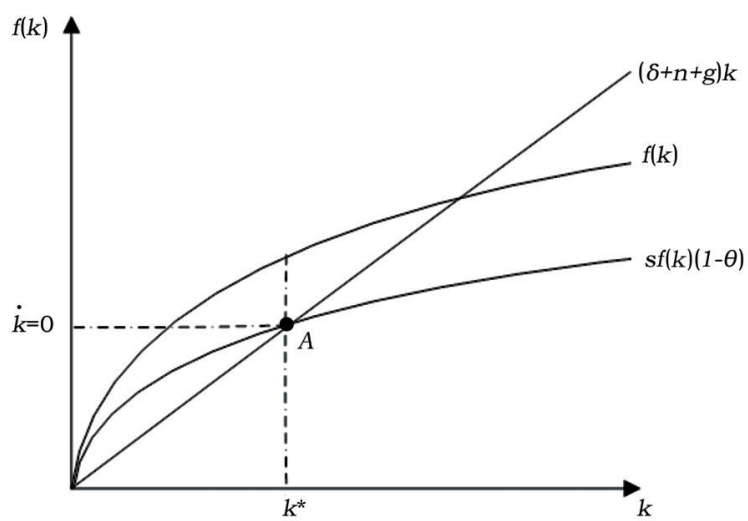

图 2 绿色索洛模型

Figure 2 Green Solow model

但由于绿色索洛模型下的实际投资水平小于标准 索洛模型,而两种情况下持平投资相等, 因此, 绿色 索洛模型中 $k^{*}$ 和 $Y$ 也都小于标准索洛模型, 这也从 理论上说明了环境因素对经济增长确实存在一定 影响。

因此,为了分析环境约束下工业用地投人对经 济增长的影响, 本文通过构建绿色索洛模型, 将土 地要素 $(N)$ 以及环境污染要素 $(E)$ 与资本要素 $(K)$ 和劳动力要素 $(L)$ 等传统要素一起作为投人要素加 人到生产函数模型中进行估算。设定的生产函数 形式为:

$$
Y(t)=F(K(t), A(t) L(t), N(t), E(t), t)
$$

式中 $t$ 为时间趋势变量。为简化形式,下文将 $t$ 省 略。为了估算要素随时期而变化的产出弹性系数, 采用C-D形式:

$$
Y=K^{\alpha}(A L)^{\beta} N^{\gamma} E^{\varphi}, \alpha, \beta, \gamma>0, \varphi<0
$$

对公式 (7)两边取对数,则构造的计量模型形 式如下:

$$
Y_{i t}=C_{i}+\alpha \ln K_{i t}+\beta \ln L_{i t}+\gamma \ln N_{i t}+\varphi \ln E_{i t}+\mu_{i t}
$$

式中 $Y$ 为产出, $K 、 L 、 N$ 和 $E$ 分别为资本、劳动力、土 地和环境等投人要素; $\alpha 、 \beta 、 \gamma 、 \varphi$ 分别测度的是这 4 种要素对总产出的弹性; $t$ 表示时期, $i$ 表示省份, $i=$ $1,2, \cdots 30 ; t=1,2, \cdots 11$ 。

\section{2 数据来源}

本文利用2000-2010年中国30个省、直辖市、自 1)证明过程如下: $k^{*}=\frac{K}{A L} \longrightarrow K=k^{*} A L \stackrel{\text { 两边取对数 }}{\longrightarrow} \ln K=\ln k^{*}+\ln A+\ln L \stackrel{\text { 对时间求导数 }}{\longrightarrow} \frac{d \ln K}{d t}=\frac{d \ln A}{d t}+\frac{d \ln L}{d t}$, 即 $\frac{\dot{K}}{K}=\frac{\dot{A}}{A}+\frac{\dot{L}}{L}=n+g$ 。 
治区的省际面板数据(由于西藏自治区数据缺失较 多, 本研究未将其纳人; 此外, 由于数据获取困难, 本次研究也不包括香港、台湾和澳门), 实证检验工 业用地投人以及环境污染对工业经济增长的影响， 并进一步对东、中、西部三个地区进行对比分析(东 部地区包括北京、天津、河北、辽宁、上海、江苏、浙 江、福建、山东、广东和海南 11 个省市; 中部地区包 括山西、吉林、黑龙江、安徽、江西、河南、湖北和湖 南 8 个省市; 西部地区包括内蒙古、广西、重庆、四 川、贵州、宁夏、新疆、甘肃、陕西、云南和青海 11 个 省市)。具体的指标选取及数据说明如下：

(1) 产出指标 $Y$ 用工业总产值(亿元) 衡量。为 了剔除物价因素的影响,按出厂价格指数折合为 2000 年不变价格。

(2) 资本存量 $K$ (亿元) 用工业固定资产净值年 平均余额代替,并按 2000 年不变价格折算。

(3) 劳动力投人要素 $L$ 量化为各省工业从业人 口数 (万人)。

(4) 土地要素 $N$ 量化为各省工业用地面积 $\left(\mathrm{km}^{2}\right)$ 。

(5)环境污染要素 $E$ 选取工业“三废”,即工业固 废产生量 $E_{1}($ 万 $\mathrm{t})$, 工业废水排放量 $E_{2}($ 亿 $\mathrm{t})$, 工业

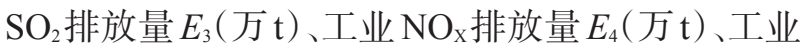
烟 (粉) 尘排放量 $E_{5}($ 万 $\mathrm{t})$ 。其中, 后三者是工业废 气的主要排放物。

工业总产值、资本存量及工业从业人口数据来 自 2001-2011 年《中国工业经济统计年鉴》[22], 表征 环境污染要素的各指标来自 2001-2011年《中国环 境年鉴》阳。

\section{4 结果及分析}

\section{1 面板数据模型设定检验}

在进行回归分析之前, 对面板数据进行协方差 检验与 Hausman 检验以判断模型的具体形式 ${ }^{[23]}$ 。模 型设定检验结果见表 1 。

关于模型形式的设定如下：

$H_{1}$ : 模型中的解释变量系数对于所有的截面成 员是相同的,但截距项不同,即该模型形式为变截 距模型;

$\mathrm{H}_{2}$ : 模型中的解释变量和截距项对于所有的截 面成员都是相同的,即该模型形式为混合回归
表 1 绿色索洛模型设定检验结果

Table 1 The test results of "Green Solo Model"

\begin{tabular}{ccccc}
\hline 检验统计量 & 全国 & 东部 & 中部 & 西部 \\
\hline$F_{2}$ & 154.65 & 86.37 & 317.39 & 111.49 \\
& $(1.00)$ & $(1.95)$ & $(2.29)$ & $(1.00)$ \\
$F_{1}$ & 58.32 & 46.80 & 30.54 & 66.84 \\
& $(1.00)$ & $(2.12)$ & $(2.29)$ & $(1.00)$ \\
Hausman 检验 & 133.06 & 97.97 & 781.53 & 24.19 \\
& $(0.00)$ & $(0.00)$ & $(0.00)$ & $(0.002)$ \\
\hline
\end{tabular}

注: $F_{2} 、 F_{1}$ 括号内为 $5 \%$ 显著水平下 $\mathrm{F}$ 统计量的近似临界值; Hausman 检验括号内数值为统计量的伴随概率。

模型。

从表 1 中可以看出, 4 个模型的 $F_{2}$ 统计量均大 于相应置信度下临界值, 即拒绝假设 $H_{2}$, 继续检验 假设 $H_{1}$ 。从 $F_{1}$ 统计量看, 均大于相应置信度下临界 值,即拒绝假设 $\mathrm{H}_{1}$, 从而得到 4 个模型均应该选择变 系数形式。另外,由 Hausman 检验结果可以看出, 在 5\%的显著水平下,4个模型均拒绝原假设(原假 设是:应建立随机效应模型）,即应建立固定效应 模型。

\section{2 回归结果分析}

为衡量土地要素及环境要素对经济增长的作 用,本文对扩展的生产函数模型进行多元回归。同 时,为进一步消除异方差的影响,采用截面加权的 方法进行估计。对 4 个模型的回归分析结果见表 2 。

从全国来看, 资本、劳动和土地要素的产出弹 性分别为 $0.53 、 0.48$ 和 0.50 , 说明在社会经济发展 中, 资本、劳动和土地投人每增加 $1 \%$, 经济增长的 幅度分别达到 $0.53 \% 、 0.48 \%$ 和 $0.50 \%$ 。环境要素 中,除工业 $\mathrm{NO}_{\mathrm{x}}$ 外, 工业固废产生量、工业废水排放 量、工业 $\mathrm{SO}_{2}$ 排放量、工业烟(粉)尘排放量对经济增 长均有显著影响。

从各地区土地要素的弹性系数来看, 东、中、西 部地区土地投人每增加 $1 \%$, 经济增长的增幅分别 为 $0.42 \% 、 0.52 \%$ 和 $0.38 \%$ 。具体来看：

(1)中部地区弹性系数最大, 这说明中部地区 经济增长对土地要素的依赖程度最高,一定程度上 限制了中部地区的产业结构升级,减缓了经济增长 的速度。中部地区自然资源丰富, 因此, 未来的发 展方向应该是充分发挥自身资源禀赋优势,在此基 础上调整和优化产业结构,才能实现经济的长期稳 
表 2 工业经济增长影响因素分地区固定效应模型 GLS 估计结果

Table 2 GLS estimation results of regional economic growth factors

\begin{tabular}{|c|c|c|c|c|}
\hline 变量 & 全国 & 东部 & 中部 & 西部 \\
\hline 截距项 & -3.588 & -3.984 & -7.902 & -2.438 \\
\hline \multirow[t]{2}{*}{ 工业资本存量/K } & $0.533 * * *$ & $0.927 * * *$ & $0.185^{* * *}$ & $0.725 * * *$ \\
\hline & (10.07) & $(8.28)$ & $(4.26)$ & $(7.38)$ \\
\hline \multirow[t]{2}{*}{ 工业从业人员/L } & $0.483 * * *$ & 0.094 & $1.107 * * *$ & $0.371 * * *$ \\
\hline & $(6.87)$ & $(0.60)$ & $(11.53)$ & $(3.11)$ \\
\hline \multirow[t]{2}{*}{ 工业用地面积 $/ N$} & $0.501 * * *$ & $0.421 * * *$ & $0.515 * * *$ & $0.377 * * *$ \\
\hline & $(9.38)$ & $(4.02)$ & $(3.51)$ & $(4.68)$ \\
\hline \multirow[t]{2}{*}{ 工业固废产生量/ $E_{1}$} & $0.357 * * *$ & $0.217 * * *$ & $0.675 * * *$ & $0.239 * * *$ \\
\hline & $(8.68)$ & $(2.85)$ & $(7.48)$ & $(4.33)$ \\
\hline \multirow[t]{2}{*}{ 工业废水排放量 $/ E_{2}$} & $-0.124 * * *$ & $-0.275^{* * *}$ & -0.155 & -0.075 \\
\hline & $(-2.99)$ & $(-3.76)$ & $(-1.41)$ & $(-1.10)$ \\
\hline \multirow[t]{2}{*}{ 工业 $\mathrm{SO}_{2}$ 排放量 $/ E_{3}$} & $-0.427 * * *$ & $-0.633 * * *$ & $-0.428 * * *$ & $-0.349 * * *$ \\
\hline & $(-8.59)$ & $(-5.99)$ & $(-4.31)$ & $(-5.30)$ \\
\hline \multirow[t]{2}{*}{ 工业 $\mathrm{NO}_{\mathrm{x}}$ 排放量 $/ E_{4}$} & -0.042 & -0.075 & $-0.204 * *$ & $-0.089 *$ \\
\hline & $(-1.18)$ & $(-0.91)$ & $(-2.64)$ & $(-1.66)$ \\
\hline \multirow[t]{2}{*}{ 工业烟 (粉)尘排放量/ $E_{5}$} & $-0.355^{* * *}$ & $-0.304 * * *$ & $-0.153^{*}$ & $-0.388 * * *$ \\
\hline & $(-8.41)$ & $(-3.19)$ & $(-1.67)$ & $(-6.11)$ \\
\hline $\operatorname{Adj}-R^{2}$ & 0.993 & 0.989 & 0.986 & 0.985 \\
\hline F-statistic & 1253.594 & 575.837 & 420.661 & 431.855 \\
\hline
\end{tabular}

注: 表中数据为各变量的弹性系数及各项系数的 $t$ 值; 上标***、**和*分别表示在 $1 \%, 5 \%$ 和 $10 \%$ 的水平上显著。

定增长。

(2)东部地区土地要素的产出弹性低于中部地 区,这主要是由于东部地区实现产业结构优化,产 业发展更倾向于资本和技术密集型的结果。伴随 经济不断发展, 土地利用集约度的提高意味着土地 将承载更多的资本、劳动力等要素, 土地要素的贡 献水平将逐步降低。

(3) 西部地区弹性系数最小。这可能是由于政 府政策导向、投资策略等发生了变化,使得西部地 区无需借助市场经济环境,便能实现资本存量的提 高, 因此放大了资本对西部经济增长的贡献力水 平, 相对缩小了土地和其他要素对经济增长的 贡献。

环境要素对经济增长的作用程度及作用方向 均存在区域差异。理论部分分析表明,环境污染对 经济的总效应的程度及作用方向取决于环境污染 正/负效应的总和。从回归结果看：

(1)工业固废变量的弹性系数均明显为正,每 增加 $1 \%$, 东部、中部、西部地区的经济增长分别提
高 $0.22 \% 、 0.68 \%$ 和 $0.24 \%$, 中部地区正处于快速崛 起阶段, 工业固废对经济增长的弹性系数相对较 大。即在目前经济发展阶段, 工业固体废弃物的产 生一定程度上能够促进经济增长。这主要是因为, 工业固体废弃物经过适当的工艺处理,可成为工业 原料或能源, 较废水、废气容易实现资源化。

(2)三个地区工业废水对经济增长的阻碍表现 为东部地区 $>$ 中部地区 $>$ 西部地区, 这主要是因为地 区经济发展水平越高, 对环境的破坏力也越大,环 境污染反过来作用于经济发展, 其阻碍作用也更加 明显。

(3) 工业废气中的 $\mathrm{SO}_{2} 、 \mathrm{NO}_{x}$ 、烟(粉)尘等的排 放对经济增长均呈显著的负向影响,这说明环境污 染一定程度上削弱了资本、劳动力和土地要素对经 济的促进作用。如果忽略工业生产的外部性, 容易 过高估计工业经济的增长效应。从要素弹性系数 的显著程度来看: 东部地区除工业 $\mathrm{NO}_{\mathrm{x}}$ 变量不显著 之外, 其他环境要素均明显抑制地区经济增长; 中 部地区和西部地区则表现为工业废水变量不显著, 
其余环境要素均十分显著。从要素弹性系数的大 小来看:工业 $\mathrm{SO}_{2}$ 的排放对东部地区的经济增长阻 碍最为明显;工业 $\mathrm{NO}_{\mathrm{x}}$ 的排放相对不利于中部地区 经济增长; 而西部地区经济增长的关键制约因素则 是工业烟 (粉)尘的排放。但三个地区存在一个共 性: 即工业废气, 尤其是 $\mathrm{SO}_{2}$ 和烟 (粉) 尘的排放对经 济增长的抑制作用较工业废水更强。这也表明工 业废气污染是以后政府需要治理环境的首要方向。

\section{5 结论与政策建议}

本文构建了内含土地和环境要素的“绿色索洛 模型”,并利用全国和东、中、西部2000-2010年省际 工业面板数据, 深人考察环境约束下工业用地投人 对经济增长的影响。主要结论如下:

(1)环境约束下, 索洛模型仍存在平衡增长路 径。这表明构建“绿色索洛模型”在理论上是可行 的,衡量工业用地投入的经济增长效应时,可以将 环境要素纳人进去进行修正。

(2)工业生产具有外部性,工业经济增长的同 时会带来一定的环境污染,形成经济增长的环境代 价。中国目前的工业经济增长仍主要依靠资本和 劳动力投人, 土地与经济增长呈现正相关, 且中部 地区土地要素对工业经济增长的贡献明显高于东、 西部地区。

(3)环境要素对工业经济增长的影响取决于正/ 负效应共同的作用结果。总体来看,除工业固体废 弃物外, 工业废水、工业 $\mathrm{SO}_{2} 、$ 工业 $\mathrm{NO}_{\mathrm{x}}$ 、工业烟(粉) 尘等的排放对经济增长均呈明显抑制作用，且工业 废气对经济增长的抑制作用较工业废水更强。

当然,实证分析的结果也揭示出忽视工业生产 的负外部性,很容易过高估计土地投人对中国工业 经济的影响。因此,借鉴绿色生产模型的核心在于 将工业经济发展中的资源成本纳人到 GDP 中, 真实 地反映工业用地投人的经济增长效应, 以期达到保 护资源和环境的目的。

经济增长的实现是有代价的, 目前中国的经济 增长很大程度上仍是通过高投人和扩大生产规模 的路径来实现的, 导致的结果就是环境遭到严重破 坏。因此,在未来的经济发展中,要摒弃“GDP”主 义的经济发展方式,积极探索建立绿色国民经济核
算体系; 同时,政府要实施创新管理,鼓励企业技术 创新,尤其是环境保护和污染治理方面的技术创 新,避免以环境容量过度透支为代价,追求工业经 济高质量、可持续增长模式。

\section{参考文献(References) :}

[1] 饶映雪,戴德艺. 工业用地供给对工业经济增长的影响研究 [J]. 管理世界, 2016, 269(2) : 172-173. [Rao Y X, Dai D Y. A study on the impact of industrial land supply on industrial economic growth[J]. Management World,2016,269(2): 172-173.]

[2] 郭贯成,熊强. 城市工业用地效率区域差异及影响因素研究 [J]. 中国土地科学, 2014, 28 (4) : 46-52. [Guo G C, Xiong Q. Study on the urban industrial land use efficiency and its influencing factors in China[J]. Chinese Journal of Soil Science, 2014,28 (4):46-52.]

[3] 谢花林,王伟,姚冠荣,等. 中国主要经济区域城市工业用地效 率的时空差异和收玫性分析 [J]. 地理学报, 2015,70(8): 13271338. [Xie H L, Wang W, Yao G R, et al. Spatial and temporal differences and convergence of China's main economic zones[J]. Journal of Geographical Sciences, 2015,70(8): 1327-1338.]

[4] 高辉娜. 工业用地对中国城市工业经济增长的贡献[J]. 城市发 展研究, 2015, 22(3) : 86-92. [Gao H N. Study on contribution of industrial land to industrial economic growth in Chinese mainland cities[J]. Urban Development Research, 2015, 22 (3): 86-92.]

[5] 高辉娜, 郭琪, 贺灿飞. 工业用地增长与工业经济增长的关系 [J]. 城市问题, 2014, (7) : 53-60. [ Gao H N, Guo Q, He C F. The relationship between industrial land growth and industrial economic growth[J]. Urban Problems, 2014, (7):53-60.]

[6] 郭贯成,温其玉. 环境约束下工业用地生产效率研究-基于中国 33 个典型城市非期望产出的考量 $[\mathrm{J}]$. 中国人口·资源与环境, 2014, 24 (6) : 121-127. [ Guo G C, Wen Q Y. Industrial land productivity research under the environmental restriction based on unexpected outputs of 33 typical cities in China[J]. China Population, Resources and Environment, 2014,24(6) : 121-127.]

[7] 陈诗一. 能源消耗、二氧化碳排放与中国工业的可持续发展 [J]. 经济研究, 2009, (4) : 41-54. [Chen S Y. Energy con-sumption, carbon dioxide emission and sustainable develop-ment in Chinese industry[J]. Economic Research Journal, 2009, (4) : 4154.]

[8 ] 杨文举. 基于 DEA 的绿色经济增长核算: 以中国地区工业为例 [J]. 数量经济技术经济研究, 2011, (1) : 19-33. [Yang W J. An accounting of green economy growth based on DEA[J]. The Journal of Quantitative \& Technical Economics,2011,(1):19-33.] 
[9] 国家统计局环境保护部. 中国环境统计年鉴[M]. 北京: 中国统 计出版社, 2001-2011. [Ministry of Environmental Protection, National Bureau of Statistics. China Environmental Statistics Yearbook[M]. Beijing: China Statistics Press, 2001-2011.]

[10] 中华人民共和国国家统计局. 中国统计年鉴[M]. 北京: 中国统 计出版社, 1996. [ National Bureau of Statistics of the People's Republic of China. China Statistical Yearbook[M]. Beijing: China Statistics Press, 1996.]

[11] 陶然,汪晖. 中国尚未完成之转型中的土地制度改革: 挑战与 出路 [J]. 国际经济评论, 2010, (2) : 93-123. [Tao R, Wang H. China's unfinished land system reform: Challenges and solutions [J]. International Economic Review, 2010, (2):93-123.]

[12］罗必良. 分税制、财政压力与政府“土地财政”偏好 [J]. 学术研 究, 2010, (10) : 33-41. [Luo B L. The tax system, financial pressures and the government "land finance" preference[J]. Academic Research,2010, (10):33-41.]

[13] 王克强,胡海生,刘红梅. 中国地方土地财政收人增长影响因 素实证研究-基于 1995-2008 年中国省际面板数据的分析 [J]. 财经研究, 2012, (4) : 112-122. [Wang K Q, Hu H S, Liu H M. Empirical study on influential factors of local land financial revenue growth in China: Analysis based on inter-province panel data from 1995 to 2008[J]. Journal of Finance and Economics, 2012, (4) : 112-122.]

[14] 王蕾. 工业园区对区域经济发展的作用研究[D]. 西安: 西安理 工大学, 2006. [Wang L. Research on the Function of Industrial Park to Regional Economic Development[D]. Xi'an: Xi'an University of Technology, 2006.]

[15］李国平,张文彬. 地方政府环境规制及其波动机理研究——基 于最优契约设计视角 $[\mathrm{J}]$. 中国人口・资源与环境, 2014, 24 (10) : 24- 31. [Li G P, Zhang W B. Analysis on the Local Government Environmental Regulation and Its Fluctuation Mechanism: Based on the Perspective of Optimal Contract Design[J]. China Population, Resources and Environment, 2014, $24(10): 24-31$.
[16] 钟茂初, 李梦洁, 杜威剑. 环境规制能否倒逼产业结构调整 [J]. 中国人口·资源与环境, 2015,25(8): 107-115. [Zhong M C, Li M J, Du W J. Can environmental regulation force industrial structure adjustment: An empirical analysis based on provincial panel data[J]. China Population, Resources and Environment, $2015,25(8): 107-115$.]

[17] 罗良文,雷鹏飞,孟科学. 企业环境寻求、污染密集型生产区际 转移与环境监管 $[J]$. 中国人口·资源与环境, 2016,26(1): 113120. [Luo L W, Lei P F, Meng K X. Corporate environmental seeking strategy, pollution- intensive production transfer and environmental regulation[J]. China Population, Resources and Environment, 2016,26(1):113-120.]

[18] 张兵兵,沈满洪. 工业用水与工业经济增长、产业结构变化的 关系 [J]. 中国人口・资源与环境, 2015,25(2):9-14. [Zhang B B, Shen M H. Relationship between the industrial water usage and the industrial economic growth and the industrial structural change[J]. China Population, Resources and Environment, 2015, 25(2):9-14.]

[19] Brock W A, Taylor M S. The Green Solow Model[R]. NBER Working Paper No.10557,2004

[20] 巴罗,萨拉・伊・马丁(著).夏俊 (译). 经济增长 $[\mathrm{M}]$. 上海: 格致 出版社, 2010. [ Robert B, Martin S Y(Write). Xia J(Translate). Economic Growth[M]. Shanghai : Gezhi Press, 2010.]

[21] Brock W A, Taylor M S. Economic Growth and the Environment: A Review of Theory and Empirics[R]. NBER Working Paper No.10854, 2004.

[22] 国家统计局工业统计司. 中国工业经济统计年鉴[M]. 北京: 中 国统计出版社, 2001-2011. [Bureau of Industrial Statistics, National Bureau of Statistics. China Industrial Economy Statistical Yearbook[M]. Beijing: China Statistics Press, 20012011.]

[23] 枆欢欢,刘荣. Eviews 统计分析与应用 $[\mathrm{M}]$. 北京: 机械工业出 版社, 2014. [Fan H H, Liu R. Eviews Statistical Analysis and Application[M]. Beijing: Machinery Industry Press, 2014.] 


\title{
The impact of industrial land input on economic growth under environmental restraints in China : analysis based on the Green Solow Model
}

\author{
DING Linlin ${ }^{1,2}$,WU Qun ${ }^{1,2}$ \\ (1. School of Public Administration, Nanjing Agricultural University, Nanjing 210095, China; \\ 2. Land Price and Market Research, Nanjing Agricultural University, Nanjing 210095, China)
}

\begin{abstract}
Environmental costs occur when industrial production promotes economic growth, leading to economic losses to some extent. Here we construct a Green Solow Model of land and environmental factors to analyze how industrial land inputs and environmental pollution impact economic growth in China with the aim of eliminating environmental costs during industrial growth. We used China' provincial panel data of 2000- 2010 to conduct empirical test simultaneously. We found that (1) under environmental constraints, the Solow Model retained balanced growth. (2) Land elements had a positive effect on economic growth, but there were differences between regions, of which the central region had the greatest impact, the eastern region followed, and the western region was the smallest. (3) How environmental factors influenced economic growth depended on the joint results of positive and negative effects. In addition to industrial solid waste, the effect of industrial wastewater, industrial sulfur dioxide, industrial nitrogen oxides, industrial dust (dust) and other emissions on the economic growth were significantly inhibited, and the inhibition of industrial emissions on economic growth was stronger than industrial wastewater. In the future economic development, we should abandon the traditional "low- cost" industrialization model, and actively explore to establish a green national economic accounting system. At the same time speed up the use of scientific and technological innovation, especially environmental protection and pollution control technology innovation, to reduce industry environmental externality in the process of land production.
\end{abstract}

Key words : industrial land input; environmental pollution; economic growth; Green Solow Model; China 